\title{
METHODOLOGICAL AND INTEGRATION ASPECTS OF ABC-METHOD APPLICATION IN TRADE ORGANIZATIONS
}

\author{
Klychova Guzaliya S. ${ }^{1}$ \& Bagaev Ilya V. ${ }^{2}$ \\ ${ }^{1}$ Klychova Guzaliya S., Dr.of economics, professor, head of account and audit department of the Kazan State \\ Agrarian University(Russia),kgaukgs@mail.ru \\ ${ }^{2}$ Bagaev Ilya V., Candidate of science in economics of the Institute of economics, management and law (Kazan)
}

\begin{abstract}
In conditions of declining consumer demand and deficit of credit resources more and more managers of Russian companies think of necessity of introducing effective methods and systems of cost management. One of the most relevant is method of "Activity Based Costing" (ABC-method). Since, in western experts' opinion sectors of service and trade are adjusted to use of ABC-method even more than production, we should refer once more to the main methodological and integration aspects of ABC-method application and consider it from position of trade organization.
\end{abstract}

Key words: ABC-method, ABB-method, allocation of costs, managerial accounting

ABC-method in trade - is the variant of forming reliable information about prime-cost of selling goods, customers in service and taking place in organization business processes (Vakhrushina M.A., 2004), exercised by means of previous distribution of consumed resources between organizations and following transference of operation cost to terminal object of calculation (goods, sales channels, etc.) (Atamanov D.Y., 2003) Schematically ABC-method can be represented in the following way (Fig. 1).

According to fig.1 all direct, relative to subjects of calculation expenses immediately referred to prime cost of respective goods, orders, clients etc., and indirect costs - go through the system of drivers, in the framework of which their distribution goes on.

After distribution of indirect costs between operations, there appears an ability to count the cost of accomplishment of each of them. As intended all operations, made in trade organization can be divided to main, service, and management. Main operations depend directly on the level of sales turnover and itself can affect on it, which conditional upon existence of between them and terminal subject of calculation (delivery operations, packing, setting out on shop window, cash services, etc.). The absence of this operations leads to work stoppage in organization (Sokolov Y. V., 2004).

Service operations are meant for creation conditions, providing normal accomplishment of main operations of the organization (equipment repair, security, stuff recruitment etc.). Presence of management operations conditioned by their interconnection with all service and main operations, since that on any area of work there is a hierarchic subordination of some employees to the others. With the application of the given classification there is a necessity in appropriation of the cost of service and management operations either on main operations or directly on subjects of calculation, for this purpose three methods can be applied (Ivashkevich V.B., 2003; Horngren C., Foster G., Datar Sh., 2007):

\begin{tabular}{|c|c|c|c|c|}
$\begin{array}{c}\text { Grouping of indirect } \\
\text { costs according to } \\
\text { responsibility } \\
\text { centers or } \\
\text { organizations } \\
\text { altogether? }\end{array}$ & drivers of & \begin{tabular}{c} 
Grouping of indirect \\
costs according to \\
operations without \\
\cline { 2 - 3 }
\end{tabular} & $\begin{array}{c}\text { expense } \\
\text { accounting organization } \\
\text { structure of trade } \\
\text { company }\end{array}$ & operations \\
Direct costs & $\begin{array}{c}\text { Terminal subjects of } \\
\text { calculation (goods, } \\
\text { clients, business- } \\
\text { processes etc.) }\end{array}$ \\
\hline
\end{tabular}

Fig. 1. General scheme of ABC-method. 
1. Method of direct distribution: expenses of service and management operations are attributed with the help of drivers to terminal subject of calculation by-passing the main operations and each other.

2. Method of step-type distribution: First, we distribute cost of service operations, accomplished in unilateral manner for the purpose of uninterrupted accomplishment of main and management operations. Then the cost of main and management operations are distributed between terminal subjects of calculation. The variety of step-type distribution is method, implying previous distribution of cost not only service, but management operations, the result of which is full attribution of costs of non main operations on main ones, the cost of which, then transferred on terminal subjects of calculation.

3. Method of mutual distribution is based on definition of the system of multitude linear equations, describing difficult circular interconnections between non main operations. with that we consider situations when:

a) service operations provide services to each other,

b) service operation provides services to management operation, which, in its turn affects on service operation.

Sometimes for the purpose of simplifying of ABCmethod the cost of service and/or management operations is not attributed neither on terminal subjects of calculating nor on main and service operations, but by analogy with the method of developed direct-cost is placed on decrease of the financial result in the end of accounting period. It is motivated by that the given expenses are "non-relative" i.e. they cannot be reasonably attributed or distributed between intermediate or terminal subjects of calculation.

Calculation of prime cost of terminal subjects of calculation in retail trading presupposes dividing into two groups: product-oriented (item, lot of goods, type of item, group of similar goods) and client-oriented (order, client, group of clients, (market segment), trade channel). In wholesale organizations enumeration of prime cost of subjects of calculation only by goods and clients is unreasonable because front office of trade organization needs to full assessment of expenses. For example, to assess profitability of selling certain lot of goods it is necessary to add prime cost of sold lot to the cost of servicing the client which has purchased that lot. Thus wholesale organization using ABC-method, compound subjects of calculation, such as "goods -clients" and "clients - goods".

Introduction of ABC-method can be implemented on the basis of its integration with other methods and systems, for example, with elements CVP-analysis, traditionally used in trade organizations. Focal point in the process of integration of ABC-method with the elements of CVP-analysis is allocation of variable in the cost of each operation i.e. variable depending on goods turnover, and constant, i.e. part independent from goods turnover. Then goes distribution of variable cost, using driver "Turnover volume", with it it's necessary to take into account interconnection of main and non main operations with terminal subjects of calculation. For example operation of pre-packing relates to only certain list of goods. Distribution of constant cost of accomplishment of each operation goes with the help of standard for ABC-method drivers. With that it should be appreciated that chosen as drivers of operations indexes must, firstly, set interconnection with terminal subjects of calculation, secondly they mustn't imitate the driver "Turnover volume". Thus, the conclusion can be made that as a result of integration with elements of CVP-analysis the methodology of ABC-method keeps being the same to a large extend, because in fact there goes additional detailing of indirect expenses, as a result of which the process of their further redistribution between terminal subjects of calculation goes on in turn - at first for the variable, then for the constant cost of each operation. (see fig.2).

After distribution cost of operations, there comes the stage of calculation of prime cost of terminal subjects of calculation. Since in the process of integration of ABCmethod with elements of CVP-analysis there takes place detailing of costs into constant and variable, forms of consolidated and pay-roll records must be added by columns, registering such detailing. Upon completion calculating accounts the analysis is carried on, the results of which are processed as a report to principal officers of trade organization. With that the analysis can be carried out both on the basis of ABC-method data, and on the basis of dividing of expenses into constant and variable (CVPanalysis), the basis of which is finding marginal profit, rate of coverage and breakeven point.

Besides more detailed analysis of the achieved results, integrated variant of ABC-method has other advantages. For

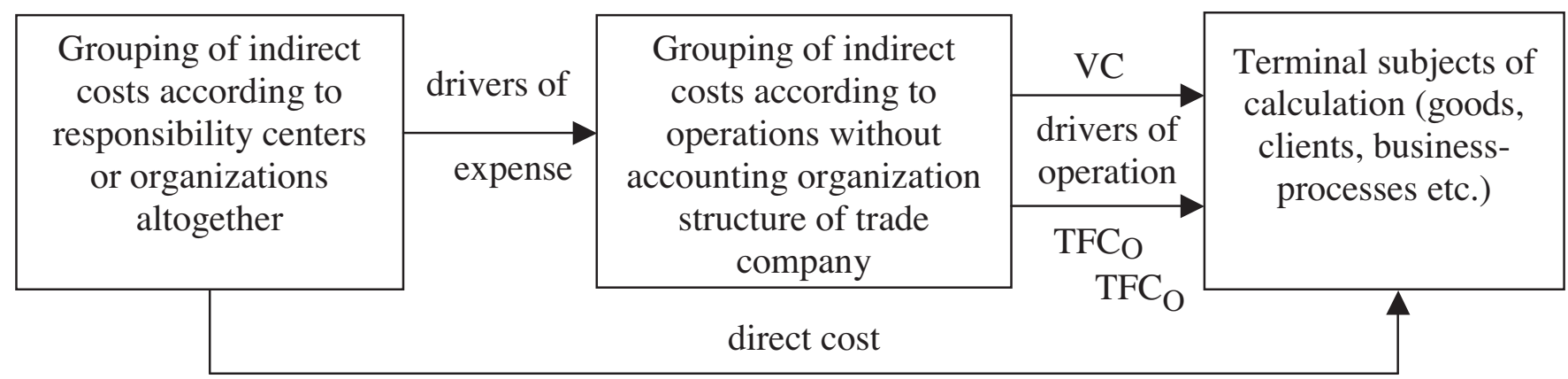

Fig.2. Scheme of ABC-method integrated with elements of CVP-analysis, where VC - variable part in operation cost, TFC - constant part in operation cost. 
instance it provides more precise calculation of prime cost of terminal subjects of calculation, in comparison with the simple ABC-method. It can be explained by that, the simple ABC-method does not take into account the variable part of cost of service and management operations, which could be distributed between terminal subjects of calculation proportionally to company's turnover. Thus the level of "irrelevance" of the given operations would be lowered. Along with that, the integrated variant of $\mathrm{ABC}$-method has an ability of previous forecasting cost of operations and terminal subjects of calculation, depending on probable increase/decrease turnover both altogether and in layout in groups of similar goods. Suppose that in the following period, expected increase in organization's total turnover on $7 \%$, which is conditioned: increase in sales volume the first group of goods on $2 \%$; increase in sales volume of the second group of goods on $6 \%$; decrease in sales volume n-group of goods on $1 \%$.

Percent terms of increase/decrease are calculated relatively to the current volume of total turnover of organization. In such case we can apply the following technique of expenses forecasting:

1. Factual variable part in the cost of each operation multiplies by coefficient 1,07 . Thus we find forecasted cost of variable part in the cost of each operation for the next month $\left(\mathrm{VC}_{\mathrm{pl}}\right)$;

2. Factual constant part in the cost of each operation remains unchanged $\left(\mathrm{TFC}_{\mathrm{f}}=\mathrm{TFC}_{\mathrm{pl}}\right)$;

3. We find total forecasted cost of each operation for the next month $\left(\mathrm{VC}_{\mathrm{pl}}+\mathrm{TFC}_{\mathrm{pl}}=\Sigma_{\mathrm{pl}}\right)$;

4. We find difference between forecasted and factual cost of each operation $\left(\Sigma_{\mathrm{pl}}-\Sigma_{\mathrm{f}}\right)$;

5. We calculate consumption factor of operations driver by terminal subjects of calculation $\left(\mathrm{d}_{\mathrm{pl}} / \mathrm{D}_{\mathrm{pl}}\right)$. With that for the common value $\left(\mathrm{D}_{\mathrm{pl}}\right)$ we take $7 \%$ forecasted increase of total turnover, and for indexes of consumption of driver by the subjects of calculation $\left(d_{p l}\right)$ - percentage value of forecasted increase/decrease of goods turnover, calculated relatively to index of the total turnover of organization of the current period;

6. We find increase/decrease of variable expenditures by the terminal subjects of calculation: $\left(\Sigma_{\mathrm{pl}}-\Sigma_{\mathrm{f}}\right) * \mathrm{~d}_{\mathrm{pl}} / \mathrm{D}_{\mathrm{pl}}$;

7. To the increase/decrease of variable indirect expenses, which was found by the terminal subjects of calculation, we add the sum of factual indirect expenses which was found by the terminal subjects of calculation in the accounting month. Integration of ABC-method with elements of CVP-analysis is able to give organization other advantages. For example, it is an ability to calculate breakeven point for service operations i.e. assess efficiency of their accomplishment. Thus we can determine the level of breakeven condition, for instance for legal department, accountants office, security department, repair service, etc. If the results of carried out analysis show that efficiency of accomplishment of service operation is lower than breakeven level, then principal office of trade organization needs to refuse to accomplish that operation or pass its accomplishment over to subcontractors.

In conditions of integration of $\mathrm{ABC}$ technique with the system of budgeting (ABB-method) budgets of commercial and administrative expenses of trade organization are replaced by multitude of budget operations, which allows forming indexes for the upcoming period more reasonably. To our opinion we can distinguish four main stages, connected to forming of budget operation indexes:

1. preparatory: finding of preliminary budget cost of operations with the help of rate of operations' drivers, calculated on the data of the past budget period, and also values of the drivers of operations of the next period.. For example, if, according to the results of trade budgeting process there was determined that sales turnover (D) of pre-packed goods will amount in January - 128473 rubles, in February - 119394 rubles, in March - 207491 rubles and so on and annual rate of the driver of operation $\left(\mathrm{r}_{0}\right)$, calculated according to the data of the past period, is 0,12 rubles/rubles, then preliminary budget cost by months will comprise:

in January: $128473 * 0,12=15417$ rubles.;

in February: $119394 * 0,12=14327$ rubles;

in March: $207491 * 0,12=24899$ rubles and so on.

2. analytical: forming and specification of cost items by each operation for the budget period. Technology of forming items of operation budgets in general view can be the following:

a) determination (specification) of the list of items of expenses, included in the cost of each operation;

b) determination of drivers for each item of expenses (drivers of expenses;

c) items of expenses are divided into dependant and independent from driver of operation, determined during the preliminary stage;

d) determination of norms of spending of drivers of dependant expenses in reliance operation driver unit;

e) the norm of spending of dependant expenses driver is multiplied by budget value of the driver of operation, as a result of which we find natural term (sometimes - at a time monetary) expression of budget item. Then natural expression of budget item is multiplied by presupposed rate of driver of expenses (hourly wages of an employee, cost of one liter of gasoline, cost of one item of packing material etc.) as a result of which we find its ruble equivalent.

f) determination of overrun or undershoot of driver of dependant expenses and its matching with the other operations, with the purpose of lowering of its overrun or undershoot. With that, for the reasoning of overrun or undershoot it's necessary as in paragraph "e" to use rates of drivers of dependent expenses; 
g) values of independent from the drivers of operations, items of expenses are determined in organization altogether, or by divisions, and then are distributed between operations proportionally to drivers of expenses (sq. meter, unit of similar equipment, etc.);

3. Calculated: finding of the final budget cost of operation accomplishment, and also finding rates of drivers of operations for the next budget period with the help of matrix form table, where horizontally is the information about items and groups of expenses, vertically - about accomplished operations in organization. If trade organization has several divisions it makes corporate-wide matrix of budget cost of operations;

4. Conclusive: calculation of the budget prime cost of the terminal subjects of calculation. The budget of prime cost consists of two parts, the first of which is made for showing the process of distribution of the budget cost of service and management operations on main operations. If distribution goes on with the help of step-type method, then the first part of budget may consist of two and more forms, since their quantity directly depends on quantity of "steps", provided by the technique of distribution (Dobrovolskiy E., Kabanov B., Borovikov P., 2006). The second part of the budget is designed to show the process of calculation of terminal subjects of calculation prime cost. With that budget cost of main operations, distributed with account of secondary expenses is added to budget value of direct cost on corresponding positions of subjects of calculation. By analogy with developed direct-cost the form of the second part of budget may have step structure which can be explained by the presence in ABB system different levels of expenses( item, installment, sort, group of goods.)

Thus ABB - method has specification, distinguishing it from traditional approach to budgeting. With that given specification affects the budget structure, ways of forming the budget indexes, and also on method of analysis and form of budgets. However, changes, necessary for the transformation of traditional system of budgeting to ABB-method do not have global character, because they accomplished only in a part of indirect (administrative and commercial) expenses, for which planning, account, control and analysis must be accomplished in another way.

\section{References}

Atamanov D.Y. (2003): Distribution of expenses at cost price accounting by the traditional and operational-focused method; Marketing in Russia and abroad. volume 3., p. 3-17.

Ivashkevich V.B. (2003): Managerial accounting. /V.B. Ivashkevich. - M.: Economist, ISBN 5-98118-033-1, p. 618.

Vakhrushina M.A. (2004): Sphere of services: the account of expenses on business processes. The accounting appendix, 2004, volume 40. p. 19-22.

Dobrovolskiy E., Kabanov B., Borovikov P. (2006): Budgeting: step by step, St. Peterburg: PITER publisher, ISBN 5-469-00712-X, p. 248

Sokolov A. Y. (2004) Managerial accounting overhead costs. Moscow: publisher Finance and Statistic, ISBN 5-279-02720-0, p. 448.

Horngren C., Foster G., Datar Sh. (2007): Managerial accounting, $10^{\text {th }}$ edition. - in translation- St. Peterburg.: Publisher PITER,. ISBN 5-94723-174-3, p. 1008. 